\title{
Sensibilidad a antibióticos, actividad antibacteriana frente a patógenos y fermentaciones ácido lácticas de una cepa nativa de Lactobacillus paracasei de origen humano
}

\author{
Vázquez, S. ${ }^{(1,2)}$, Lopretti, M. ${ }^{(1,2)}$, Rey, F. ${ }^{(1)}$, Zunino P. ${ }^{(3)}$ \\ (1) Departamento de Biotecnología y Bioprocesos, Laboratorio Tecnológico del Uruguay, LATU - (2) Laboratorio de \\ Bioquímica y Biotecnología, Centro de Investigaciones Nucleares, Facultad de Ciencias, Universidad de la República, \\ Uruguay - ${ }^{(3)}$ Departamento de Microbiología, Instituto de Investigaciones Biológicas Clemente Estable, Uruguay. \\ Contacto: frey@latu.org.uy \\ Recibido: 02/03/2010 - Aprobado: 28/10/2010
}

\begin{abstract}
$\underline{\text { Resumen }}$
El objetivo de este trabajo fue caracterizar una cepa nativa de Lactobacillus paracasei aislada en el Departamento de Bioprocesos y Biotecnología del Laboratorio Tecnológico del Uruguay (LATU). Se realizaron fermentaciones ácido lácticas (FAL) en leche, a los efectos de determinar las características de crecimiento de la cepa. Se evaluaron tres cinéticas en las FAL: los ácidos orgánicos determinados por titulación en leche, la acidificación del medio a lo largo de las fermentaciones por medidas directas de $\mathrm{pH}$ sobre el medio y la biomasa producida en $10 \mathrm{ml}$ de cultivo.

Asimismo, se evaluó la actividad antimicrobiana frente a un patógeno gastrointestinal como Salmonella sp. por análisis de discos impregnados con diferentes concentraciones del probiótico. También se determinó la sensibilidad a dicloxacilina y penicilina por medio de un antibiograma modificado.

La cepa exhibió buen crecimiento en leche, con curvas de crecimiento típicas de bacterias lácticas. Se detectaron los halos de inhibición del crecimiento de Salmonella sp. dependiendo de la concentración bacteriana. Fueron obtenidas las curvas de inhibición del crecimiento bacteriano en función de las concentraciones de antibiótico.

En conclusión, esta cepa de Lactobacillus paracasei aislada de materia fecal humana es un prometedor candidato a ser usado en la preparación de productos probióticos.

Palabras clave: Probióticos, actividad antimicrobiana, antibióticos, cinética.
\end{abstract}

\begin{abstract}
$\underline{\text { Abstract }}$
The objective of this study was the characterization of a native Lactobacillus paracasei strain isolated at the Bioprocesses and Biotechnology Department of the Technological Laboratory of Uruguay (LATU). Lactic acid fermentations were made in order to determinate the strain growth's characteristics. We evaluated three kinetics: the organic acids by titration in milk, acidification of the medium throughout the fermentation by $\mathrm{pH}$ measurement and biomass produced in $\mathbf{1 0} \mathrm{ml}$ of culture medium.

The anti-microbial activity against Salmonella sp. a gastrointestinal pathogen, was tested by means of a disk diffusion test. Sensitivity to penicillin and dicloxacillin was assayed through a modified antibiogram.

The strain showed good growth in milk, with growth curves characteristic of lactic bacteria. Halos of growth inhibition of Salmonella sp. were detected depending on the bacterial concentration. Curves were obtained for inhibition of bacterial growth as a function of concentrations of antibiotic.

In conclusion, this strain of Lactobacillus paracasei isolated from human faeces is a promising candidate to be used in the formulation of probiotic products.

Keywords: Probiotic, antimicrobial activity, antibiotics, cinetic.
\end{abstract}

\section{Introducción}

Los probióticos, microorganismos vivos que cuando son administrados en cantidades adecuadas confieren un efecto benéfico en la salud del huésped (FAO, WHO, 2001), han sido incorporados en tabletas, cápsulas y derivados lácteos como las leches fermentadas, leches acidófilas dulces, yogur y, más recientemente, queso (Saito, 2004; Taranto et al., 2005). Por este motivo las cepas probióticas seleccionadas para ser utilizadas en la industria láctea deben ser capaces de crecer y vivir en leche, así como proporcionar características sensoriales aceptables.

El consumo de productos probióticos favorece la capacidad de restablecer la flora intestinal tras episodios de diarrea en niños, y de interferir con patógenos, por mecanismos de competencia de la adhesión o por la producción de sustancias antibacterianas (Senok et al., 2005; Ballabriga, 2001; Reid, 1999). Es por esta razón que uno de los criterios de selección de probióticos es la capacidad de inhibir el crecimiento de patógenos gastrointestinales como Salmonella sp., Shigella sp. y Escherichia coli (Annuk et al., 2003; Saarela et al., 2005; Calderon, et al., 2007).

En trabajos anteriores los autores reportaron el aislamiento y la caracterización fenotípica de una cepa nativa de Lactobacillus sp. con propiedades que permiten clasificarla como una posible cepa probiótica (Vázquez et al., 2007). El objetivo de este trabajo fue continuar la caracterización de dicha cepa realizando fermentaciones ácido lácticas (FAL) en leche a los efectos de determinar las características de su crecimiento. Asimismo, se evaluó la actividad antimicrobiana frente a un patógeno gastrointestinal como Salmonella sp. y se determinó la sensibilidad a dicloxacilina y penicilina. 


\section{Materiales y Métodos}

\section{Cepas bacterianas}

La cepa denominada HA-9 nativa de origen humano fue identificada como Lactobacillus paracasei por ensayos moleculares. La misma se encuentra disponible en el Banco de Cepas del Laboratorio Tecnológico del Uruguay (LATU).

La cepa de Salmonella sp. pertenece al banco de cepas del LATU $\mathrm{y}$ es de origen alimenticio.

\section{Fermentaciones Ácido Lácticas}

Se realizaron fermentaciones en leche a los efectos de determinar las condiciones de crecimiento de la cepa. Para el desarrollo del inóculo se realizó un cultivo overnight de la cepa, transfiriendo tres o cuatro colonias de un cultivo fresco en medio MRS-agar a un tubo con $10 \mathrm{ml}$ de leche libre de semisólidos reconstituida al $10 \%$ y previamente tratada térmicamente $\left(100{ }^{\circ} \mathrm{C}, 30\right.$ minutos, sin presión). El cultivo se incubó a $37^{\circ} \mathrm{C}$ durante 16 horas en jarra de anaerobiosis y luego se centrifugó a 3.500 g por 30 minutos y se resuspendió en suero fisiológico, ajustando la concentración inicial por absorbancia a $560 \mathrm{~nm}$ en $1 \times 10^{9}$ unidades formadoras de colonias (ufc). Luego se transfirieron volúmenes de inóculo a matraces que contenían $500 \mathrm{ml}$ de leche descremada tratada térmicamente, de modo que la concentración inicial fuera de $1 \% \mathrm{v} / \mathrm{v}$.

Al inicio del ensayo (tiempo cero) se tomaron cuatro muestras de la siguiente forma: $7 \mathrm{ml}$ para determinar acidificación por peachímetro (744 pH Meter Metrohm), $10 \mathrm{ml}$ para determinar acidificación por titulación con $\mathrm{NaOH} 0.1 \mathrm{~N}$ (producción de ácidos orgánicos), 0,1 $\mathrm{ml}$ para determinar $\mathrm{ufc} / \mathrm{ml}$ por recuento en placa de MRS y $10 \mathrm{ml}$ para determinar la biomasa producida. Los matraces se colocaron en estufa a $37{ }^{\circ} \mathrm{C}$ sin agitación y el crecimiento se evaluó por 29 horas, realizando tomas a diferentes tiempos. Como control se procedió de forma análoga con un matraz sin inocular. La titulación se llevó a cabo según norma ISO 6091:1980 con soda $0.1 \mathrm{~N}$, con fenolftaleína como indicador. Para determinar la biomasa se centrifugó cada toma a $3.500 \mathrm{rpm}$ durante 30 minutos (Hettich Zentrifugen D-7200). Los sobrenadantes se descartaron y los tubos se colocaron en estufa a $40{ }^{\circ} \mathrm{C}$ hasta peso constante (aproximadamente ocho días), que se determinó por pesada directa en balanza analítica (Mettler Toledo AG204).

\section{Sensibilidad a antibióticos}

A los efectos de determinar el comportamiento de HA92 frente a diferentes antibióticos, se realizó un ensayo empleando discos de papel de filtro impregnados con diferentes concentraciones de penicilina y dicloxacilina (Bauer et al., 1966).

Brevemente, HA92 se cultivó en $10 \mathrm{ml}$ de caldo MRS en jarra de anaerobiosis a $37{ }^{\circ} \mathrm{C}$ por $18-24$ hs. Posteriormente se esparcieron $200 \mu \mathrm{l}$ del cultivo en la superficie de las placas de MRS agar sobre las cuales se colocaron discos de papel de filtro estériles impregnados con $20 \mu \mathrm{l}$ de diferentes concentraciones de dicloxacilina (SIGMA concentraciones entre $0,15-2,5 \mu \mathrm{g} / \mathrm{ml}$ ) y penicilina (SIGMA $10 \mathrm{MU}$ concentraciones entre $0,09-1,32 \mu \mathrm{g} / \mathrm{ml}$ ). Las placas fueron incubadas por 24 horas en condiciones anaerobias a $37^{\circ} \mathrm{C}$. Se determinaron los diámetros de los halos de inhibición alrededor de los discos, los cuales se graficaron en función de la concentración del antibiótico. Como control se utilizaron discos sin impregnar. Fueron conducidos tres ensayos independientes por triplicado.

\section{Actividad antibacteriana frente a patógenos}

Para evaluar la capacidad de la cepa HA92 de inhibir el crecimiento de un patógeno gastrointestinal como Salmonella sp., se realizó un ensayo de discos sobre agar con modificaciones (Jacobsen et al., 1999; Fraga et al., 2005).
En resumen, $20 \mu 1$ de un cultivo fresco de HA92 (concentraciones entre $1 \times 10^{4}$ y $1 \times 10^{8} \mathrm{ufc} / \mathrm{ml}$ ) fueron inoculados sobre discos de papel de filtro previamente esterilizados y colocados sobre una placa de agar MRS. La placa fue incubada por 24 horas en jarra de anaerobiosis y luego cubierta con $10 \mathrm{ml}$ de agar $(1,5 \%)$ inoculado con un cultivo fresco de Salmonella $\mathrm{sp}$. $(1 \times 108 \mathrm{ufc} / \mathrm{ml})$ e incubada a $37^{\circ} \mathrm{C}$ en condiciones aerobias. Los posibles efectos inhibitorios del MRS fueron testeados en cada placa. La capacidad de inhibición del crecimiento fue determinada por medidas de la zona de inhibición que rodea el disco. Se condujeron tres ensayos por triplicado.

\section{Resultados y Discusión}

\section{Fermentaciones Ácido Lácticas}

De las curvas de producción de ácidos orgánicos y variación del pH (productos del metabolismo primario) se puede inferir que la bacteria mostró una fase lag de aproximadamente cuatro horas (Gráfico 1). La producción de ácidos orgánicos correspondió con la acidez producida en el medio, el pH inicial fue de 6,65, y llegó a 5,83 a las 25 horas. El pH óptimo de $L$. paracasei es de 5,4 - 5,8, por lo que la bacteria nunca se encontró bajo condiciones óptimas de $\mathrm{pH}$. El desarrollo de la acidez no necesariamente se debe a los ácidos orgánicos producto del metabolismo de la lactosa, sino que también puede provenir de otros productos de fermentación.
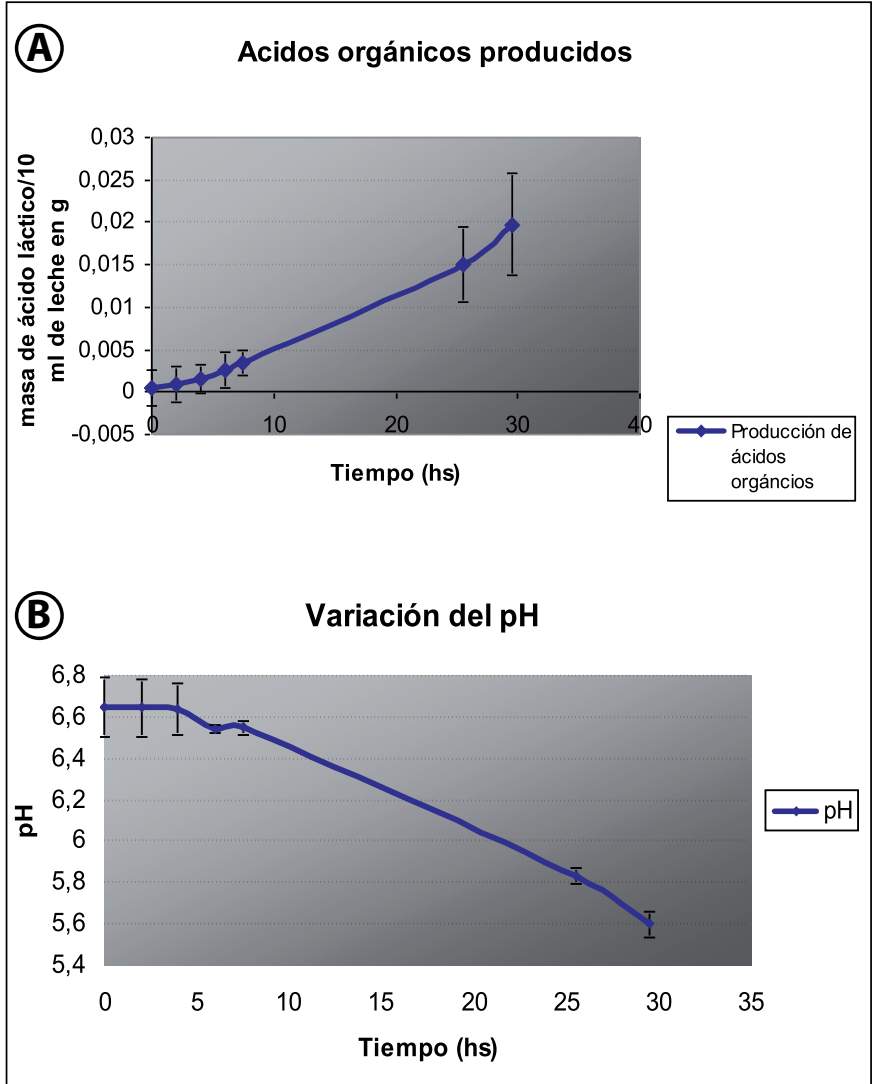

Gráfico 1. a) Producción de ácidos orgánicos en leche determinados por titulación del medio de crecimiento. b) Variación del pH en 29 horas de fermentación.

La curva de biomasa en función del tiempo (Gráfico 2) presenta una fase lag de alrededor de cuatro horas de duración, que se corresponde con los ácidos orgánicos generados en el medio de crecimiento. La fermentación comenzó con una concentración bacteriana de aproximadamente $10^{6} \mathrm{ufc} / \mathrm{ml}$, y al cabo de 29 horas, ya en fase estacionaria desde la hora 8 , el recuento se ubica en el orden de $10^{7}$ unidades. 
En futuros ensayos se modularán las condiciones de concentración inicial y de incubación con el fin de alcanzar la concentración de células bacterianas necesarias para obtener un producto con propiedades de probiótico.

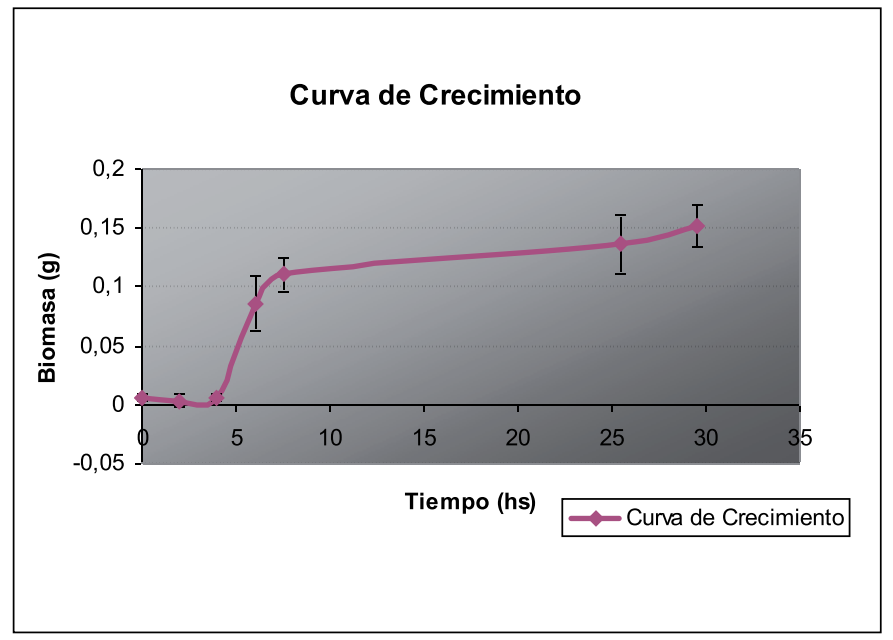

Gráfico 2. Curva de crecimiento en leche determinada por la biomasa (expresada en g) producida en $10 \mathrm{ml}$ de cultivo durante 29 horas.

\section{Sensibilidad a penicilina y dicloxacilina}

De la lectura de las curvas de sensibilidad de la cepa a la penicilina (SIGMA 10MU) se puede afirmar que en las condiciones del ensayo la concentración mínima de inhibición se encuentra en el entorno de los $0,062 \mu \mathrm{g} / \mathrm{ml}$ (Gráfico 3, Figura 1). En el caso de la dicloxacilina (SIGMA), la concentración mínima de inhibición es menor a 0,1562 $\mu \mathrm{g} / \mathrm{ml}$. Los discos utilizados como control no presentaron zonas de inhibición, por lo que los halos de inhibición del crecimiento se debieron exclusivamente a la acción de las diferentes concentraciones de antibiótico utilizadas en el ensayo.

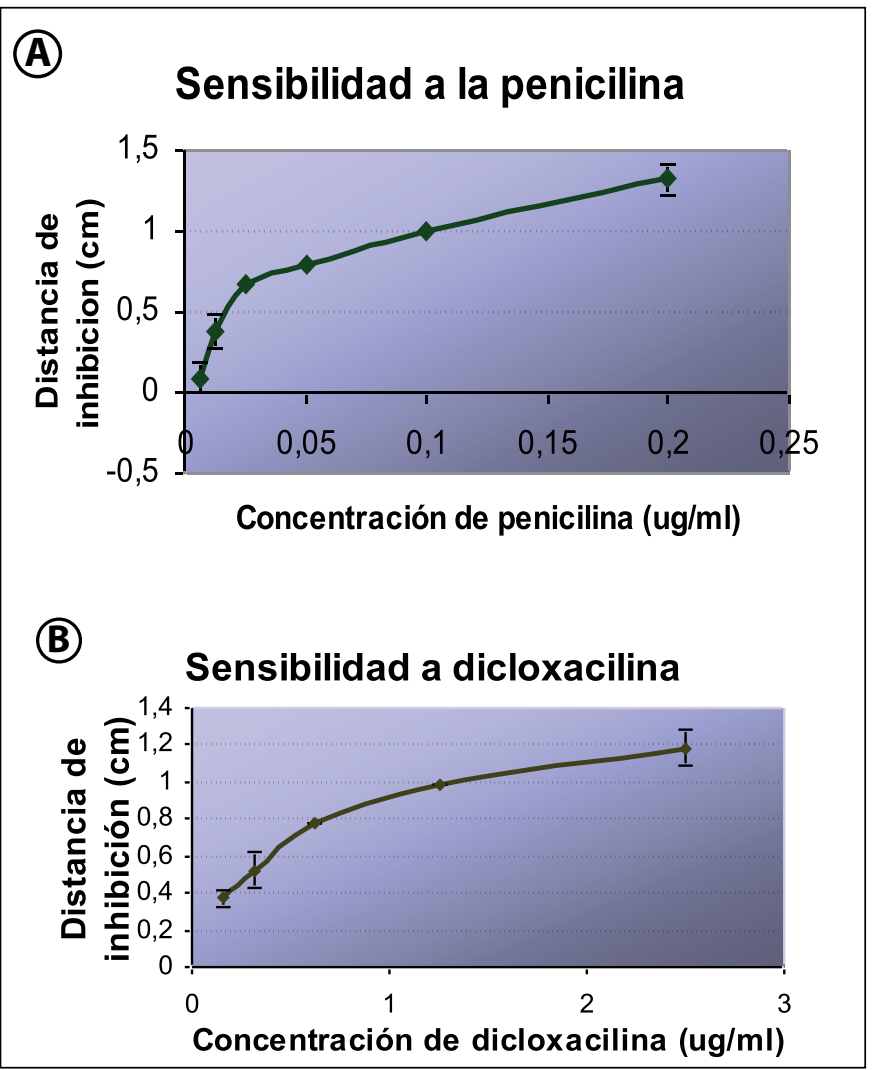

Gráfico 3. a) Curvas de sensibilidad a penicilina y b) dicloxacilina de la cepa expresada en función de la distancia de inhibición a diferentes concentraciones de antibiótico.
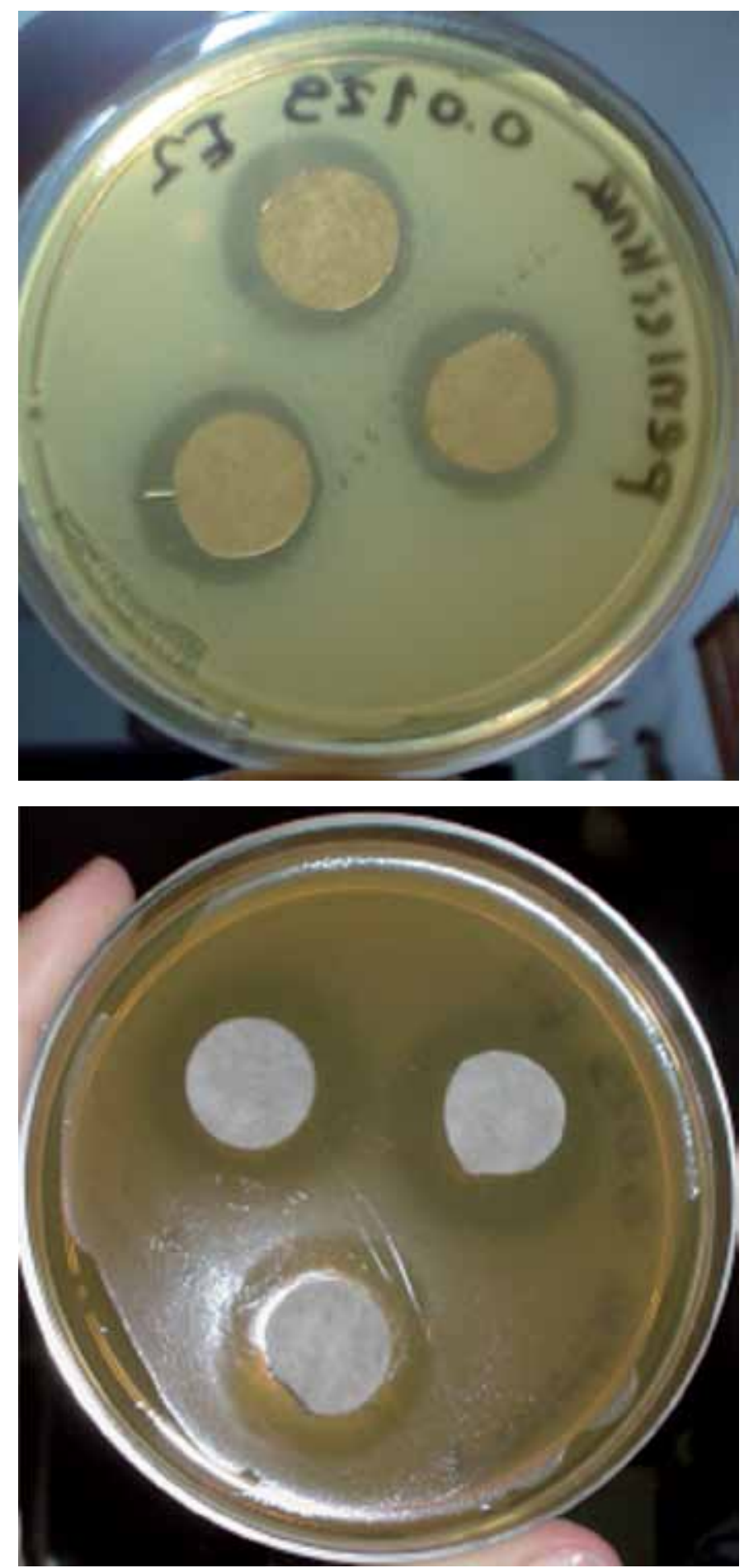

Figura 1. Ensayo de discos para penicilina (arriba) y dicloxacilina (abajo).

\section{Actividad antibacteriana frente a patógenos}

De los resultados de la capacidad de la cepa en estudio de presentar actividad antibacteriana frente a un patógeno gastrointestinal por medio de la inhibición de su crecimiento (Gráfico 4), se observa que a concentraciones del Lactobacillus inferiores a $1 \times 10^{6}$ no se evidencia inhibición del crecimiento de esta cepa de Salmonella sp. (concentración $1 \times 10^{8} \mathrm{ufc} / \mathrm{ml}$ ). A concentraciones superiores se produce un halo de inhibición de entre 19 y $21 \mathrm{~mm}$. En las zonas de la placa lejanas al crecimiento del Lactobacillus no se observó inhibición del crecimiento.

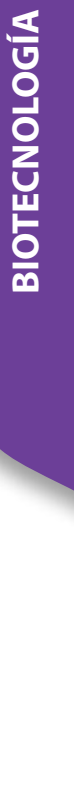




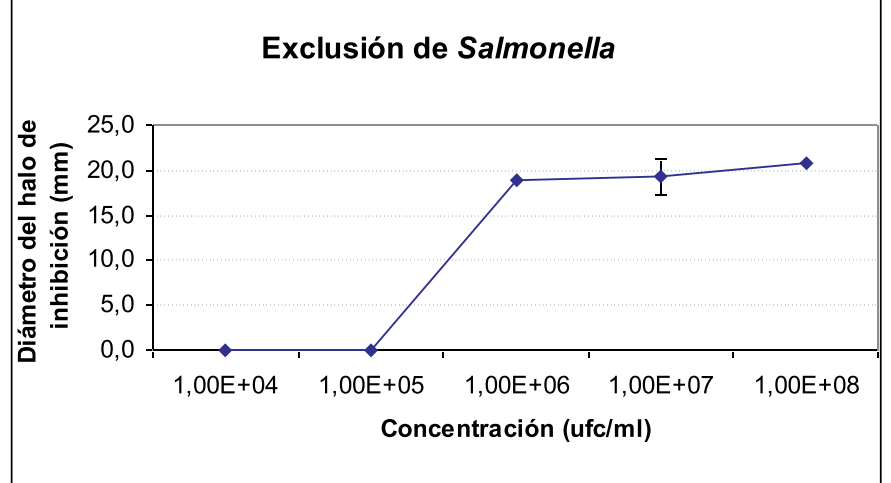

Gráfico 4. Diámetros de inhibición del crecimiento de Salmonella (mm) vs las diferentes concentraciones de la cepa HA9-2 utilizadas.

\section{Conclusiones}

La cepa exhibió buen crecimiento en leche. Por las características del crecimiento, puede concluirse que sería posible obtener la biomasa necesaria para su empleo como probiótico.

La presencia de halos de inhibición del crecimiento de Salmonella sp. hace pensar que HA9-2 produce alguna sustancia difusible con actividad antibacteriana. Los discos utilizados como control no presentaron zonas de inhibición, por lo que los halos de inhibición del crecimiento se deben exclusivamente a la acción de dicha sustancia. El hecho de que no se presenten zonas de inhibición en regiones de la placa lejanas al crecimiento del Lactobacillus permite inferir que la inhibición del crecimiento no se produjo por ningún efecto del MRS.

También fueron obtenidas las curvas de inhibición del crecimiento bacteriano en función de las concentraciones de dos antibióticos. La posible sensibilidad frente a los antibióticos testeados aparecería como ventajosa en caso de administración en humanos, ya que una cepa con distintas resistencias podría representar un potencial peligro para la salud del consumidor.

En conclusión, esta cepa de Lactobacillus paracasei aislada de materia fecal humana es un prometedor candidato para ser utilizado en la preparación de productos probióticos.

\section{Referencias}

- ANNUK, H.; SHCHEPETOVA, J.; KULLISAAR, T.; SONGISEPP, E.; ZILMER, M.; MIKELSAAR, M.

Characterizacion of intestinal lactobacilli as putative probiotic candidates. En: Journal of Applied Microbiology. 2003, (94):403412.

- BALLABRIGA, A. Nutrición en la infancia y adolescencia. Madrid: Ergon, 2001. pp. 625-662

- BAUER, A.; KIRBY, W.; SHERRIS, J.; TURCK, M. Antibiotic susceptibility testing by a standardized single disk method. En: Am. J. Clin. Pathol 2006, 45(4):493-496.

- CALDERÓN, O.; PADILlA, C.; CHAVES, C.; VILLALOBOS, L.; ARIAS, M. Evaluación del efecto del cultivo probiótico Lactobacillus rhamnosus adicionado a yogur natural y con probióticos comerciales sobre poblaciones de Staphylococcus aureus, Escherichia coli O157:H7, Listeria monocytogenes y Salmonella enteridis. En: Archivos Latinoamericanos de Nutrición. 2007, 57(1):1-6.

- FAO; WHO. Health and nutritional properties of probiotics in food including powder milk with live lactic acid bacteria. Córdoba: FAO, 2001.

- FRAGA, M.; SCAVONE, P.; ZUNINO, P. Preventive and therapeutical administration of an indigenous Lactobacillus sp. strain against Proteus mirabilis ascending urinary tract infection in a mouse model. En: Antonie van Leeuwenhoek. 2005, 88(1):25-34.

- INTERNATIONAL DAIRY FEDERATION (Belgium). IDF 86:

Dried milk, Determination of titratable acidity reference method. Brussels: IDF, 1981.

- JACOBSEN, C.N.; ROSENFELDT, N.V.; HAYFORD, A.E.; MOLLER, P. L.; MICHAELSEN, K. F.; PAERREGAARD, A.; SANDSTROM, B.; TVEDE, M.; JACOBSEN, M. Screening of probiotics activities of forty seven strains of Lactobacillus spp. by in vitro techniques and evaluation of the colonization ability of five selected strains in humans. En: Applied Environ. Microbiology 1999, 65(11):4949-4956.

- REID, G. The scientific basis for probiotic strains of Lactobacillus. En: Applied Environ. Microbiology. 1999, 65(9):3763-3766.

- SAARELA, M.; MOGENSEN, G.; FONDEN, R.; MATTILASHANDHOLM, T.; MÄTTÖ, J. Probiotic bacteria: safety, functional and technological propierties. En: Journal of Biotechnology. 2000, 84(3):197-215.

- SAITO, T. Selection of useful probiotic lactic acid bacteria from the Lactobacillus acidophilus group and their applications to functional foods. En: Animal Science Journal. 2004, 75(1):1-13. - SENOK, A.C.; ISMAEEL, A.Y.; BOTTA, G.A. Probiotics: facts and myths. En: Clin. Microbiol. Infect. 2005, 11(12):958-996.

- TARANTO, M.P.; MÉDICI, M.; FONT DE VALDEZ, G. Alimentos funcionales probióticos. En: Química Viva. 2005, 4(1):26-34.

- VÁZQUEZ, S.; LOPRETTI, M.; REY, F.; ZUNINO, P. Aislamiento y caracterización de cepas nativas de Lactobacillus spp. para su uso como probióticos en la industria láctea. En: INNOTEC. 2007, (2):12-14. 